report also notes that a breeder programme would involve full-scale commitment to the plutonium cycle with its attendant proliferation problems. In spite of those drawbacks, however, the panel doesn't recommend complete abandonment of the programme, but suggests instead that the effort should be sharply reduced in priority and be pursued only as "insurance" against the possibility of very high future energy costs or the failure of efforts to develop altcrnative energy sources.

The effort to develop a commercial breeder reactor has long enjoyed pride of place as the federal government's most expensive and most controversial energy research and development programme. The expected cost of the programme has soared from $\$ 2,000$ million to $\$ 12,000$ million in the past few years, and the projected date for introduction of commercial breeder reactors has slipped from the late 1980 s to the mid 1990s. A small test reactor, the Fast Flux Test Facility, is now nearing completion in Washington State and it is expected to start operations in 1980 . The plan is to follow that with a $380 \mathrm{MW}$ demonstration reactor, construction of which was expected to begin on the Clinch River in Tennessee this year, with operation scheduled for 1983. The next step would be a large prototype reactor, funded chiefly by electricity utilities, with construction scheduled to begin in 1981 and operation in 1988. A decision on whether to proceed from the prototype to a fullscale commercial programme would be made in 1986.

The Ford Foundation study suggests that the overlapping, crash programme leading to a decision on commercialisation as early as 1986 is unwarranted, and it recommends that the effort be completely revamped with more emphasis placed on technology development. In particular, the panel recommends that the Clinch River plant be abandoned, and it suggests that the decision on commercialisation can safely be postponed beyond the end of the century.

Again, that recommendation meshes neatly with Carter's campaign pledge to reduce the breeder programme to a "relatively low priority, possibly multinational effort". Last month, moreover, Carter recommended that nearly $\$ 200$ million be cut from the Ford Administration's budget request for the breeder programme, and he ordered the Energy Research and Development Administration to undertake an intensive study of the need for and timing of the effort. That study is now under way, for ERDA established last month a committee containing some of the breeder programme's most vocal supporters and critics, and asked it to come up with recommendations before Carter's 20 April energy statement.

The Ford Foundation panel also urges the Carter Administration to take a number of other steps to reduce pressures leading to nuclear proliferation. In particular, it suggests that "the United States must have a clear policy on its long-term role in providing enriched fuel to both domestic and foreign nuclear power programs". The government should retain ownership of uranium enrichment facilities, the panel recommends, thereby reversing the Ford Administration's goal of turning enrichment plants over to private industry. The United States should also ensure that there is ample enrichment capacity in the 1980 s and 1990 s to meet international commitments, for the panel suggests that an assured fuel supply would reduce the incentive for other countries to develop their own enrichment and recycling facilities.

Finally, the panel recommends that the government should proceed promptly with plans to test the feasibility of disposing of nuclear wastes in salt beds and other stable geologic formations. Decisions on waste disposal have been continually deferred, pending introduction of reprocessing, a fact which has led to the widespread belief that reprocessing is an essential pre-requisite for permanent disposal (a belief which is written into legislation in Germany requiring that reactor wastes be reprocessed before disposal). The panel notes, however, that "spent fuel can be disposed of directly, and probably at costs comparable to those for reprocessed wastes".

\section{SERI site selected}

Thе Energy Research and Development Administration (ERDA) last week conferred a much sought after plum on the State of Colorado. It selected a site in the Denver suburbs for the long-awaited Solar Energy Research Institute (SERI), a facility which could develop into the leading solar energy research centre in the United States.

Altogether nineteen organisations in 16 different states had been vying for SERI during the past year; the winner is the Midwest Research Institute, a St Louis-based research organsiation, which teamed with Colorado to offer a proposal.

To help soften the blow for some of the unlucky contenders, ERDA also announced last week that it will establish three regional solar energy research centres in New England, the Southeast, and the upper Midwest. The regional centres are expected to be run by consortia including representatives of several state governments, though their full role in the overall solar effort has yet to be determined.
SERI was called for in the Solar Energy Research, Development and Demonstration Act, a bill passed in 1974 which directed ERDA to establish a national facility and to seek the advice of the National Academy of Sciences on its role and scope. It was generally anticipated that SERI would be a large facility along the line of ERDA's nuclear laboratories.

The Academy furthered that expectation with a report recommending that SERI should be a major operation responsible for all phases of solar energy research including photovoltaics, fuels from biomass, wind power and so on. SERI should have a large budget, amounting to about $\$ 50$ million by 1980 , the Academy suggested. With very few large scientific projects up for grabs these days, such a big-league enterprise immediately generated a lot of attention and proposals came flooding into ERDA.

Early last year, however, ERDA, under pressure from the Office of Management and Budget, opted for something rather less grandiose. It announced that SERI would start small-a budget of about $\$ 5$ million for its first year-and a decision would be made early in the 1980 s on whether it should be expanded to the sort of facility the Academy had in mind. Even that scaled-down version attracted 20 separate bids, however, and ERDA shortlisted 19 of them for further study.

In announcing the selection of the Midwest Research Institute/Colorado proposal, ERDA Acting Administrator Robert Fri said last week that SERI will start with a budget of \$4-6 million for its first year, and a staff of about 75 professionals. It will cover all aspects of solar energy, but initially its functions will be mostly concerned with assessments, analyses, information dissemination, education and consultation. Its research and development activities will build up more slowly, and ultimately it could be moved to its own 300-acre site nearby at the foot of the Rocky Mountains.

Colin Norman 